ARTICLES 


\title{
Oria, condesa del Pallars: una dama catalana del siglo XII
}

\author{
J.E. Ruiz-Domènec \\ Universitat Autònoma de Barcelona. Institut d'Estudis Medievals. \\ 08193 Bellaterra (Barcelona). Spain
}

\section{Resumen}

El documento número 3410 encontrado en el fondo de la Cancilleria de l'Arxiu de la Corona d'Aragó lleva al auror a elaborar la fisonomía de una de las grandes damas catalanas del siglo XII: Oria de Pallars que, junto a las también damas de este condado Llúcia de la Marca, Valença de Tose y Guillelma, son para él claves en la tistoria de Cataluña.

\section{Abstract. Oria, countess of Pallar: A caralan lady of the Xuth century}

The document number 3410, found in the fund of the Cancilleria de l'Arxiu de la Corona d'Arago (Chancellery of the Records of the Aragon Kingdom) led author to describe the physiognomy of one of the great catalan ladies of the XIIth century: Oria de Pallars who is a key figure in the history of Catalonia, together with the other ladies of this county, Llúcia de la Marca, Valença de Tost and Guillelma.

Ahora que decido afrontar por segunda vez el mundo de las mujeres del siglo XII, el trabajo de archivo ha sido como unas vacaciones para mí; por eso mismo quizás me volqué en él con un obstinado buen ánimo, encantado de tener la oportunidad de investigar nuevamente como lo había hecho veinticinco años atrás cuando elaboré mi tesis doctoral. En esta ocasión, más que agobiarme por los resultados o protestar por la aridez de los pergaminos, he conseguido avanzar con alegría, recreándome en mi propio esfuerzo. Yo sigo creyendo en el difícil reto que supone conocer el mundo de las mujeres al margen de las fuentes literarias, pero ahora quiero trazar la fisonomía de algunas grandes damas catalanas del siglo XII sin necesidad de recurrir, al menos de momento, a lo que nos dicen de ellas las canciones o las novelas. Supongo que con ello quiero demostrar de qué modo se puede elaborar la imagen de la mujer a partir de los escasos documentos que nos han llegado de aquella lejana época. El primer ejemplo que aquí presento es el de Oria, condesa del Pallars, una gran dama catalana del siglo xII.

El conocimiento que tuve de esta mujer fue totalmente por azar. Una tarde de la primavera de 1995 , mientras ordenaba los documentos que iba 
a utilizar en el estudio de Alfonso, rey de Aragón, conde de Barcelona y marqués de Provenza ${ }^{1}$, un pergamino llamó mi atención. Era ya hora avanzada, eso lo recuerdo, cuando sentí esa sensación de haber topado con uno de esos documentos que sirven de punto de partida para nuestras investigaciones. Figuraba con el número 3410 Extrainventario en el fondo de la cancillería del Archivo de la Corona de Aragón. No era conocido: ni siquiera Ferran Valls i Taberner lo menciona en su excelente trabajo sobre los condes del Pallars ${ }^{2}$. Cuando me detuve en leerlo, dejando de momento a un lado los pergaminos que me habían llevado por segunda vez al archivo, vi que se trataba sin embargo de un documento excepcional. En contrapartida, el documento tiene el inconveniente de no presentar fecha alguna. Pero eso no debe importarnos demasiado. Tras un breve cotejo con otros documentos sobre esta mujer ${ }^{3}$, estoy seguro que se escribió en torno al año 1150 , momento en que la sociedad catalana estaba recibiendo el impacto de la unión dinástica entre Petronila, reina de Aragón y Ramón Berenguer IV, conde de Barcelona. Luego, y mientras lo transcribia con sumo cuidado como debe realizarse siempre este abnegado pero necesario trabajo ( $\mathrm{y}$ en principio lo hacía por simple curiosidad, sin ningún motivo ulterior), pude comprobar que la información contenida era mucho más rica de lo que en príncipio había llegado a creer. He aquí las palabras que escribió, tal como aparecen reflejadas en el documento:

In Dei nomine e eius gratia. Hec est memoria de illas fidanzas que dedi comite Paliarensis ad uxoren suam, dopnam Oria, die que eam accepit; et sunt fidanzas Frontin e Giem Ramon senescalch ut teneat eam gent et adononore secundum suum posse omnibus diebus vite suae sana e infirma, et ille quod non laxet eam nisi per cucuzia probata et combatuta illa stando in sua chasa de illo chomite et in sua honore; et sunt fidanzas de sus tres dotes Roderic Petrez de Orrea et Do Artal de Alaon ubi illa se adotaverit ad suos parentes per illa in suas hereditates ac illo chomite.

El documento, como se ve, es muy interesante: se trata del reconocimiento de la memoria de los juramentos (fidanzas) que la condesa Oria recibió el día en que fue llevada a la casa y al honor de su esposo. El dato es fundamental, pero necesita ser interpretado de acuerdo con la manera que tengo de ver la sociedad catalana de este tiempo.

1. Ruiz-DOMENEG, J.E. Alfonso, rey de Aragón, conde de Barcelona y marqués de Provenza. (Discurso de ingreso en la Real Academia de Buenas Lerras de Barcelona, leído el 29 de febrero de 1966). Barcelona: RABLB/UAB, 1996.

2. VALLS TABERNER, Ferran, "Els origenes dels comtats de Pallars i Ribagorçan, en Estudis Universitaris Catalans, IX, Barcelona, 1915-16, p. 1-101.

3. Por cjemplo, el 22 de junio de 1149 tiene lugar la sconveniencia ... inter Arnaldum Mironis, comitem, et Oriam, comitissam, et Rogerium de Eroles» (ACA, Real Patrimonio, clase 1* A 10. Edita P. Miquel Rosell, Liber Feudorum Maior. Barcelona, 1949. Apéndice n. 83 , vol. II, p. 373). 
Desde hace años insisto en la necesidad de reconstruir los linajes de la aristocracia catalana de los siglos XI y XII, convencido de que en la época feudal la memoria transita por la genealogia. Esta vez he dispuesto los materiales para reconstruir el linaje de los condes del Pallars. Una tarea difícil. En un momento importante de la historia de este linaje aparece Oria. Su figura no ha llamado mucho la atención de los eruditos, que la suelen despachar a toda prisa: Oria, de la casa de los Entenza. Poco más se dice de ella. En tan parcas palabras se adivinan sus apuros en cada momento, pero al mismo tiempo se afañan por justificar la decisión tomada. El sentido de la responsabilidad me impide seguir este tipo de lecturas: el documento que encontré es lo suficientemente importante como para desmentir estos trabajos. La *memoria» de Oria habla de ella como hija, esposa, como madre: estas tres funciones acompañan la realidad de su vida. Pero, en este momento, surgen los auténticos problemas. Oria es esposa de Arnau Mir del Pallars Jussà, y madre de Ramón V, conde del Pallars: eso está claro. Algunos documentos coetáneos asi lo demuestran. Pero, ¿̨e quién es hija? A pesar de la importancia de su papel como esposa y madre, la figura de esta dama solo es posible entenderla si llegamos a saber con exactitud el linaje del que procede. El matrimonio feudal es una unión de dos unidades familiares, de dos linajes, un acuerdo entre hombres, por medio de una mujer que uno de ellos entrega a otro. ¿Quién entregó a Oria a Arnau Mir? El mismo que obligó a firmar los juramentos (fidanzas), el mismo que confiere estatus a esta mujer al margen de su papel matrimonial.

La tarea está por hacer. Adelanto una hipótesis en cierto modo arriesgada. Oria fue uno de los eslabones principales en la cadena genealógica de los condes del Pallars, tras su escisión a comienzos del siglo xI. Hacia 1140 fue cedida por el hermano de su madre, Garsenda (una mujer que estaba casada con Bernat de Entenza, un feudatario menor de los condes del Pallars), por su avunculus, que yo interpreto que era el poderosísimo conde Artau II del Pallars Sobirà; y hago por tanto que Garsenda sea hija de Artau I y de Lucía de la Marca, la hermana de Almodis, la mujer de Ramón Berenguer I. Me apoyo para establecer esta hipótesis en el documento de la memoria de Oria, en la que contemplo un verdadero rito de paso de la casa del padre (o el hermano) a la del marido, por medio de unos juramentos entre hombres. La filiación de Oria es fundamental en la estructura de parentesco de los condes del Pallars, como lo es de su madre Garsenda: dos mujeres destinadas a terminar con la grave "escisión" que se produjo a principios del siglo $\mathrm{x}$ cuando los hijos de Sunyer, Guillem II Sunyer y Ramon II Sunyer se dividieron el Pallars. Pero de momento no puedo ir más allá. Necesito buscar los documentos del condado del Pallars Sobirà donde es posible halle explicación a muchas sombras actuales.

Más conmovedor resulta aún ver como Oria del Pallars desafió a su marido, el conde Arnau Mir, un hombre duro, que nunca aceptó de buen grado la presencia de esta dama, obstinándose en buscar la forma de marginarla de los derechos de sucesión de su hijo. En un primer momento, el 22 de septiembre de 1157 , intenta que su condado pase a la orden militar del Hospital, una cos- 
tumbre muy extendida entonces y que contaba con la legitimidad de haber sido la actitud adoptada por el rey Alfonso el Batallador ${ }^{4}$; luego, y tras permanecer prisionero del rey de Navarra en 1164, rectifica, y el 9 de noviembre de 1171 deja el condado a su hijo, y coloca a su esposa en el justo lugar que le correspondía según lo pactado entre ambos "cum scripto in dotem et sponsaliciumn.

Tras la muerte de Arnau Mir en 1174, Oria se convirtió en una viuda amable y rica que planificaba su vida en el interior de un monasterio, en principio a la sombra de su hijo Ramón V (que se había casado con Anglesa de Cardona en 1167), y que era en ese momento sucesor de su padre en el condado del Pallars. Luego, sola pero liberada del control masculino que le había atenazado toda su vida, el de su tío materno, el de su esposo, el de su hijo, planificó su última voluntad. Escribió su testamentos. Una nueva forma de dar a luz, pero esta vez no por su vientre sino por su abundante riqueza, más exactamente por su dinero, pues todo el patrimonio mobiliario le venía por herencia paterna, por ese Bernat de Entenza, un hombre de la frontera, que como el famoso Arnau Mir de Tost, padre de la abuela de Oria, había conseguido del pillaje en tierras musulmanas. De ese dinero se sirvió para reconstruir los monasterios y las iglesias de su tierra. Así fue como se aplicó a una tarea que me parece propia de las mujeres: el mantenimiento de la liturgia.

Otro aspecto difícil de la vida de Oria, pero tejido de perspectivas de gran alcance para el conocimiento de la historia del condado del Pallars, es la función de Oria como donante. Sus acciones puntuales, precisas, en el momento adecuado, tienen la precisión de una actitud intencionada consciente frente a un peligro que amenazaba el orden social y religioso del condado del Pallars. Oria se enfrenta con plena decisión ante este problema. Debemos juzgar a Oria por sus acciones $y$ sus donaciones piadosas. De sus donaciones, yo adivino alguna de ellas, pero las creo subordinadas a lo que esta gran dama deseaba hacer, su gran designio en la vida, aunque ignoro los pasos que le condujeron a adoptar una actitud tan firme ante el avance de la herejía por sus tierras: esa herejía que provenía del otro lado del Pirineo y que entraba por el Valle de Arán hacia el corazón mismo del condado del Pallars. Era necesario contener esas ideas que tanto fascinaban a las mujeres de aquel tiempo. Oria se elevó por encima de las demás damas. Por eso mereció el honor de ser representada en el ábside de San Pedro de Burgal y, por supuesto, al retrato (por decirlo de esta manera tan inexacta) de su condesa donante.

La donante de Burgal concentra todos los problemas que trato de investigar en adelante, los problemas del significado del condado del Pallars. Es conocido el hecho que Josep Pijoan identificó a la donante de Burgal con Guillelma, la esposa del conde Bernat del Pallars, como también es conocido que Joan Ainaud de Lasarte sostuvo que era Lucía, la esposa del conde Artau I del Pallars.

4. VALLS I TABERNER, op, cit. p. 56 y ss.

5. ACA, Cancilleria, perg. Alfons I, n, 240 (edita P. MIQufl, Roselt, Liber Feudorum Maior, doc. 144). 
La cronologia de la donante de Burgal es una de las escasas fechas que permiten datar la pintura mural del románico del Pallars. ¿Quién era en realidad esta mujer?

La fragilidad de la investigación se pone aquí de manifiesto. La inscripción situada sobre la cabeza de la donante de Burgal reza asi: «...ia comitisan. De no ser por esos escasos centímetros que faltan al comienzo de la terminación del nombre, la historia sería muy diferente. Es como para dar un ataque a cualquiera que se interese por estos asuntos. La terminación «... ian concentra todo un problema cronológico. Si esa donante es Lucía «comitisan del Pallars, estamos ante una pintura de finales del siglo XI, pero si por el contrario la terminación «....ia» se refiere a Oria, también "comitisa» del Pallars, estaríamos ante unas pinturas de mediados del siglo XII.

La decisión de quién es la condesa donante de Burgal es un suceso crucial, no solo para el conocimiento de las mujeres del siglo XII, sino para la historia de la cultura catalana. Las observaciones de los especialistas no aclaran demasiado el problema. El áspero debate sobre la datación de las pinturas de los ábsides de las iglesias del condado del Pallars (San Juan de Bohi, San Clemente de Tahull, Santa Maria de Tahull, Esterri de Cardós, San Pedro de Sorpe, Santa Maria de Mur, San Quirce de Pedret, Santa Maria de Esterri de Áneu, San Juan de Tredós, $y$, por supuesto, San Pedro de Burgal) es un asunto difícil de resolver. Cada nueva hipótesis es recibida con recelo, pues obliga a revisar todo el conjunto. Una cosa me parece clara: la gran pintura románica del condado del Pallars está bajo la protección de las condesas viudas de este linaje. Deberemos analizar con sumo cuidado la actividad de cuatro de ellas, en el período más álgido de la producción artística del Pallars, entre 1082 y 1196 : Lucía de la Marca, Valencia de Tost, Oria del Pallars, Guillelma del Pallars.

Necesito avanzar una nueva hipótesis, mientras reuno los materiales de estas mujeres. La donante de Burgal es Oria, condesa del Pallars. Se podría pensar que este cambio de interpretación terminará por beneficiar el estudio de la pintura mural del Pallars, aunque no estoy seguro, pues la realidad es que nos acostumbramos rápidamente a dar por sentado ciertas lecturas que luego no son firmes del todo. Al fin y al cabo la decisión es tan frágil como las anteriores, aunque tiene la ventaja de situar la figura de la donante en unos años en los que parece más seguro se hicieron todas estas pinturas. Eso es lo que ocurre con la ornamentación de Santa Maria de Mur. Mientras persigo nuevos datos que permitan legitimar (o desmentir) esta hipótesis, me parece buen punto de partida la identificación de la donante con Oria. Si pudiera estar un poco más seguro, gran parte de nuestros problemas se resolverían. Pero una vez más los deseos no coinciden con la realidad documental. Otras pruebas confirman la hipótesis, $y$ así, poco a poco fui descubriendo que estaba de nuevo en el punto de partida de un estudio de las mujeres del siglo XII. Tenía un retrato delante de mí. Debía interpretarlo. Necesitaba que la hermenéutica avanzara en esta dirección. A eso se reducia la historia de estos últimos meses. Clifford Geerz salió en mi ayuda, también de modo inesperado. De sus lecturas volví a comprender el significado de la obra de arte. Después de muchos 
años de no tenerla en cuenta, aprendí que todo lo que quería saber de las mujeres del siglo XII se encontraba en esta imagen femenina del ábside de Burgal. Por razones que no logro comprender del todo, siento que he llegado al fondo de la cuestión.

Observemos su retrato. Los ojos de la condesa del Pallars son inquietos y brillantes, de un pardo amarillento; casi del mismo tono que su pelo. Un pelo recogido como era costumbre en todas las mujeres casadas (o viudas). No lleva velo. Sus cejas son un poco más oscuras que el pelo. Gruesas y casi horizontales, ponen de relieve la profundidad de los ojos. Es más atractiva que hermosa. Su rostro fascina por la indudable franqueza de su expresión y una contradictoria y sutil combinación de facciones. No hay en su semblante rastro alguno de preocupación; y sus ojos recogian y reflejaban la luz y la languidez de un día de verano en el Pirineo. Su porte es seductor. Un fuerte cuello soportado por un incipiente bocio. La condesa del Pallars extiende su brazo izquierdo con la palma de la mano hacia adelante (en la derecha lleva un cirio). Una rica túnica cubre su cuerpo en estado grácil, casi incorpóreo, atento a la fiesta litúrgica que tenía lugar en ese momento. En el exterior el viento, los árboles, la gente que se había reunido para acompañar a la condesa a ese acto festivo.

Esta bella imagen de mujer, casi sin interpretar, nos llega a través del tiempo, de esos ocho siglos que nos separan de ella, ya que los gestos, o la mirada, indican un mundo en convulsión, que necesita comprender el sentido de esa amenaza que se vislumbraba a lo lejos. Oria lo presintió más que ninguna otra mujer de su tiempo en el condado del Pallars: ¿̨Fue por instinto o por esa convicción que logró tras una difícil vida matrimonial? A veces me digo que lo más importante de la historia de las mujeres del siglo XIr está presente aquí, en la vida y en la obra de Oria. 